\title{
Unmet Need for Family Planning among Married Women of Reproductive Age in An Egyptian Village
}

\author{
${ }^{1}$ Sherehan Adel Abdelsalam, ${ }^{2}$ Samar El-Desouky El-Sayed, ${ }^{3}$ Mohamed Azmy Khafagy \\ ${ }^{1}$ Doaa Shokry Alemam
}

${ }^{1}$ Community Medicine Department, Faculty of Medicine, Mansoura University, Egypt.

${ }^{2}$ Ministry of Health and Population, Egypt. ${ }^{3}$ Community Medicine Department, Faculty of Medicine, Mansoura University, Egypt

Submission Date: 20-01-2021Ｒevision Date: 09-02-2021 Acceptance Date: 10-02-2021

\begin{abstract}
Background: Women with unmet need for family planning (FP) comprise an enormous part of married women of conceptive age in developing countries. In 2015, the estimated percentage of married women with unmet for FP was estimated as $12 \%$. Many socioeconomic and reproductive factors influence the high prevalence of unmet need. Objective: The study was conducted to estimate the contraceptive prevalence rate and the percent of unmet need and to investigate the determinants of unmet needs among studied women. Methods: A cross sectional study with analytical components was carried out between January and May 2019 at Shoha primary health care center, Mansoura District, Dakahlia Governorate on 400 currently married women in childbearing age. A questionnaire used to obtain both socio-demographic and reproductive data. Result: The prevalence of unmet need for family planning was $9.8 \%$. The risk of unmet need was 2.46 more times among working women and 3.39 more times among women having children aged less than two years Conclusion: A considerable proportion of rural Egyptian women still have an unmet need. The need for more effective FP program is very crucial in combating this problem.
\end{abstract}

Keywords: Unmet need - family planning - working women - rural

Corresponding Author: Doaa shokry Alemam; Email: dr_doaashokry@hotmail.comdr_doaashokry@mans.edu.eg

\section{Introduction}

Family planning (FP) is defined as the capacity for individuals and couples to accomplish their desired number of children and plan the spacing and timing of their births through utilization of contraceptive methods. ${ }^{1}$ The benefits of family planning have a developing been acknowledged all over the world, including improved health, economic, and social outcomes for women and families, as well as public health, economic, and environmental benefits at the population level. At the individual level, health benefits for women and children incorporate decreasing morbidity and mortality for both of them. ${ }^{2}$ There are many indicators to assess success of family planning. One of them is unmet needs for contraception which is defined as the percentage of married women who reveal no wish to get pregnant and, at the same time, don't use any method of contraception to achieve that purpose. ${ }^{3}$ Globally, in 2015, the estimated percentage of married women with unmet for FP was estimated with $12 \% .^{4}$ Women

Oct. 
with an unmet need for family planning actually comprise an enormous part of married women of conceptive age in developing countries. Unmet need is particularly prevalent in West and Central Africa (where an unmet need for spacing births predominates) and is less common in Latin America and Asia. ${ }^{5}$

As compared to many other countries in the region, the percentage of contraception use in Egypt is higher with lower of unmet need for FP. Unfortunately, this situation was reversed over the past two decades. According to the latest Egypt Demographic and Health Survey (EDHS) 2014, unmet need for FP elevated from $11.6 \%$ in 2008 to $12.6 \%$ in 2014 with decrease of contraception use from $60 \%$ to $58 \%$ in the same period. ${ }^{6}$ In a recent study analyzing the overall unmet need for FP it was found to be $11.2 \%$ in a sample of rural married sexually active women in their childbearing. ${ }^{7}$ However, it was higher than the overall rate of unmet need previously reported by Sultan et al in Cairo, Egypt $(7.4 \%) .{ }^{8}$ Previous higher rates of unmet need were revealed by El- Gendy et al in Banha, Mohamed in Ismailia and Braghi et al in Assiut $(30 \%, 15.7 \%$ and $24.5 \%$ respectively). ${ }^{9}, 10,11$

Thinking about explanations behind not utilizing contraception, it was discovered inconsistent sexual activity and concerns respect to side effects and health risks associated with contraceptive methods to be the most widely recognized explanations behind nonuse. Other causes as opposition of the partner to contraception and religion role. ${ }^{12}$

Having updated estimate of the level of unmet need for family planning is important for monitoring progress of family planning programs and assessing where there is need for increasing efforts overall, increasing support in regions or adjusting the goals, policies and programs.
The current study aims to assess the unmet needs of contraception among married females in childbearing age $(18-49)$ in an Egyptian village to explore common reasons for unmet need and to find out the determinants of unmet needs among them.

\section{Method}

Study design and setting: A cross sectional study with analytical components was carried out between January and May 2019 in primary health care center in Shoha village, Mansoura District, Dakahlia Governorate. This village was selected as it was accessible and had a cooperative health unit team.

The study included 400 currently married women in childbearing age (18-49 years).

Inclusion criteria: All married, sexually active women, aged (18-49) years. Exclusion criteria: Women not yet sexually active (as due to travelling of the husband) aged (18-49) and mentally incapacitated women.

The calculated sample size of the study was 282 at $5 \%$ level of significance, $5 \%$ precision and $90 \%$ power of the study, using the following formula. ${ }^{13}$

$$
\mathrm{N}=\frac{\mathrm{Z}^{2 *} \mathrm{P} *(1-\mathrm{P})}{\mathrm{d}^{2}}
$$

$\mathrm{Z}=2.58$ at $95 \%$ confidence level.

$\mathrm{P}=$ expected prevalence of women with unmet needs $(12 \%)$ as reported by ElMasry et al in Egypt. ${ }^{7}$

$\mathrm{d}=$ precision $($ margin of error) $=0.05$

The sample size was increased to 420 participants to compensate for sheets with incomplete data and to increase the study power.

Sampling method: Systematic random sampling was utilized to select 400 married females recruited from family files at the family medicine center in the village. This center was selected as it is big center and covered large number of residents. 
Every third married female was selected to be included in the study. The total of 420 married females in childbearing period with

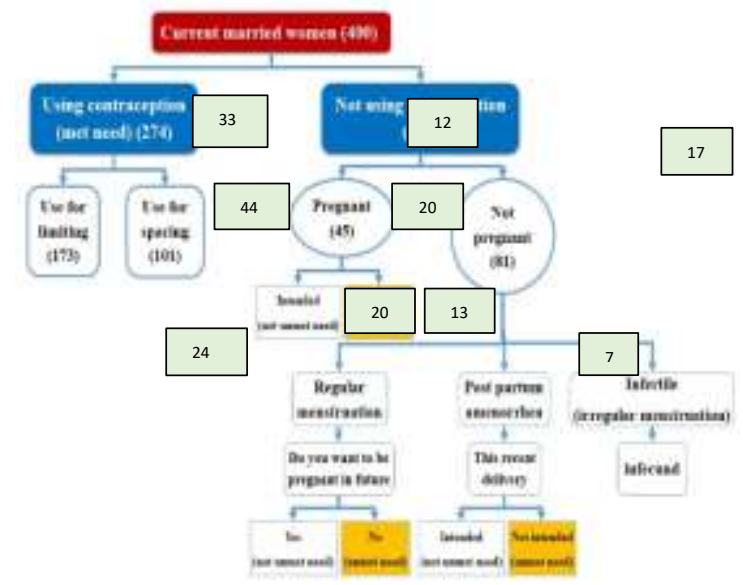

Figure (1): Flow chart of distribution of studied women according to their current state of contraceptive use

response rate $95 \%$ (400), which included in the study.

Data was collected through a validated interviewer administered questionnaire (Arabic form). ${ }^{7}$ The questionnaire included questions about the following data: (1) Socio-demographic characteristics such as age, education, occupation, duration of marriage. (2) Detailed reproductive history: as gravidity and parity, history of abortion, Number of living children, gender of living children, age of youngest child, types of last delivery, history of unintended pregnancy, menstruation, past history of contraception, different contraceptive methods, reasons for discontinuation if any.

The size of unmet need estimated according to the revised definition of women with unmet need for family planning. A woman is considered to have unmet need if she is at risk of becoming pregnant, not using contraception, want no more children or pregnant with an unwanted pregnancy or postpartum amenorrheic for up to 2 years following an unwanted birth and not using contraception. $^{14}$

\section{Data analysis}

Data were coded, entered and statistically analyzed using the Statistical Package for Social Science (SPSS) version 21. Qualitative data were described using Table (1): Reasons for non-use of family planning methods among unmet need group.

\begin{tabular}{|c|c|c|}
\hline \multirow{2}{*}{ Reasons for non-use * } & \multicolumn{2}{|c|}{ Study group $(n=39)$} \\
\hline & No & $\%$ \\
\hline \multicolumn{3}{|l|}{ Fertility related reasons } \\
\hline Infrequent sex & 9 & 23.0 \\
\hline Lactation & 8 & 20.5 \\
\hline Older age & 7 & 17.9 \\
\hline Sub fecundity & 3 & 7.7 \\
\hline \multicolumn{3}{|l|}{ Methods related reasons } \\
\hline Fear of side effects & 17 & 43.5 \\
\hline Can't reach FP method & 2 & 5.1 \\
\hline \multicolumn{3}{|l|}{ Opposition to use } \\
\hline Husband opposed & 5 & 12.8 \\
\hline Religious prohibition & 4 & 10.2 \\
\hline
\end{tabular}

* Categories are not mutually exclusive

number and percent. Association between categorical variables was tested using Chisquare test. Binary stepwise logistic regression analysis was used for prediction of independent variables. Significant predictors in the bivariate analysis were entered into regression model using forward Wald method. Adjusted odds ratios and their $95 \%$ confidence interval were calculated. $\mathrm{P}$ value $\leq 0.05$ was considered to be statistically significant.

\section{Ethical consideration}

The research protocol was approved by IRB (Institutional Research Board) of Faculty of medicine with number MS/16.12.63. Oral consent was obtained from all subjects. All obtained information was kept confidential. Results

The current study included 400 married women of reproductive age, the unmet needs among studied females represents 
9.8\% and contraceptive prevalence rate (met need) is $68.5 \%$ (figure1). The most frequent reasons for nonuse of contraception among females with unmet needs are; fear of side effects $(43.5 \%)$, Table (2): Socio-demographic characters among met group versus unmet group

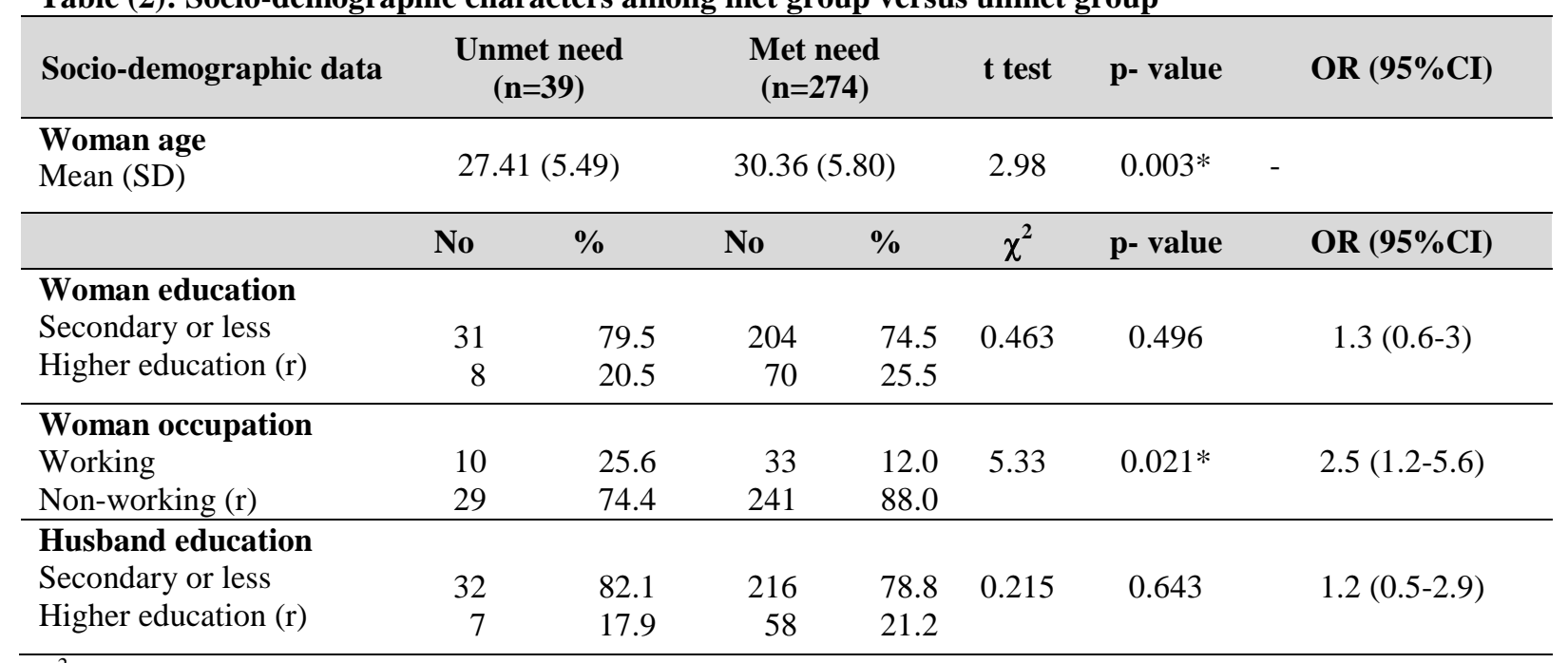

$\chi^{2}$ : Chi square test, CI: confidence interval, OR: odds ratio, * significant $p<0.05$

(r): reference group

Table (3): Reproductive characteristics among met group versus unmet group

\begin{tabular}{|c|c|c|c|c|c|c|c|}
\hline \multirow{3}{*}{$\begin{array}{l}\text { Duration of marriage } \\
\text { Mean (SD) }\end{array}$} & \multicolumn{2}{|c|}{$\begin{array}{l}\text { Unmet need } \\
\qquad(n=39)\end{array}$} & \multicolumn{2}{|c|}{ Met need $(n=274)$} & \multirow{3}{*}{$\begin{array}{c}\text { t test } \\
2.52 \\
\chi^{2}\end{array}$} & \multirow{3}{*}{$\begin{array}{c}\text { p- value } \\
0.012 * \\
\text { p- value }\end{array}$} & \multirow{3}{*}{$\begin{array}{c}\text { OR }(95 \% \mathrm{CI}) \\
- \\
\text { OR }(95 \% \mathrm{CI})\end{array}$} \\
\hline & \multicolumn{2}{|c|}{$7.69(4.84)$} & \multicolumn{2}{|c|}{$10.01(5.43)$} & & & \\
\hline & No & $\%$ & No & $\%$ & & & \\
\hline $\begin{array}{l}\text { Gravidity } \\
\leq 3 \\
>3(\mathrm{r})\end{array}$ & $\begin{array}{r}30 \\
9\end{array}$ & $\begin{array}{l}76.9 \\
23.1\end{array}$ & $\begin{array}{r}194 \\
80\end{array}$ & $\begin{array}{l}70.8 \\
29.2\end{array}$ & 0.628 & 0.428 & $\begin{array}{c}1.4(0.6-3.02) \\
1\end{array}$ \\
\hline $\begin{array}{l}\text { No of living children } \\
\leq 3 \\
>3(\mathrm{r})\end{array}$ & $\begin{array}{r}34 \\
5\end{array}$ & $\begin{array}{l}87.2 \\
12.8\end{array}$ & $\begin{array}{r}226 \\
48 \\
\end{array}$ & $\begin{array}{l}82.5 \\
17.5\end{array}$ & 0.536 & 0.464 & $\begin{array}{c}1.4(0.53-3.9) \\
1\end{array}$ \\
\hline $\begin{array}{l}\text { Gender composition } \\
\text { Boys } \\
\text { Girls } \\
\text { Both (r) }\end{array}$ & $\begin{array}{r}9 \\
5 \\
24\end{array}$ & $\begin{array}{l}23.1 \\
12.8 \\
61.5\end{array}$ & $\begin{array}{r}59 \\
52 \\
163 \\
\end{array}$ & $\begin{array}{l}21.5 \\
19.0 \\
59.5\end{array}$ & $\begin{array}{c}0.007 \\
0.69 \\
- \\
\end{array}$ & $\begin{array}{c}0.932 \\
0.406 \\
- \\
\end{array}$ & $\begin{array}{c}1.03(0.5-2.3) \\
0.6(0.23-1.8) \\
1\end{array}$ \\
\hline $\begin{array}{l}\text { Age of youngest child } \\
\leq 2 \mathrm{y} \\
>2 \mathrm{y}(\mathrm{r})\end{array}$ & $\begin{array}{r}33 \\
6 \\
\end{array}$ & $\begin{array}{l}84.6 \\
15.4 \\
\end{array}$ & $\begin{array}{l}146 \\
128 \\
\end{array}$ & $\begin{array}{l}53.3 \\
46.7 \\
\end{array}$ & 13.69 & $<0.001 *$ & $\begin{array}{c}4.8(1.9-11.9) \\
1 \\
\end{array}$ \\
\hline $\begin{array}{l}\text { Type of last delivery } \\
\text { VD (r) } \\
\text { CS }\end{array}$ & $\begin{array}{r}8 \\
31 \\
\end{array}$ & $\begin{array}{l}20.5 \\
79.5\end{array}$ & $\begin{array}{r}91 \\
183 \\
\end{array}$ & $\begin{array}{l}33.3 \\
66.7\end{array}$ & 2.54 & 0.11 & $\begin{array}{c}1 \\
1.9(0.8-4.4) \\
\end{array}$ \\
\hline $\begin{array}{l}\text { History of abortion } \\
\text { yes } \\
\text { No (r) }\end{array}$ & $\begin{array}{l}11 \\
28\end{array}$ & $\begin{array}{l}28.2 \\
71.8\end{array}$ & $\begin{array}{r}74 \\
200\end{array}$ & $\begin{array}{l}27.0 \\
73.0\end{array}$ & 0.025 & 0.875 & $\begin{array}{c}1.1(0.5-2.2) \\
1\end{array}$ \\
\hline
\end{tabular}


Table (2) shows that the risk of unmet needs is higher among younger woman (OR: $0.91, \quad 95 \%$ CI: 0.85-0.97) and 2.5more times among working women (OR: 2.5, 95\% CI: 1.2-5.6). The risk of unmet needs is common among women

Table (4): Logistic regression analysis of independent predictors of unmet need

\begin{tabular}{lccc}
\multicolumn{1}{c}{ Independent predictor } & $\boldsymbol{\beta}$ & P - value & OR (95\% CI) \\
\hline Woman age (continuous) & -0.092 & 0.004 & $0.91(0.85-0.97)$ \\
\hline $\begin{array}{l}\text { Woman occupation } \\
\begin{array}{l}\text { Working } \\
\text { Non-working (r) }\end{array}\end{array}$ & 0.902 & 0.038 & $2.46(1.05-5.8)$ \\
\hline Duration of marriage (continuous) & -0.090 & 0.014 & $0.90(0.85-0.98)$ \\
\hline $\begin{array}{l}\text { Age of youngest child } \\
\leq 2 \mathrm{y}\end{array}$ & 1.222 & 0.021 & $3.39(1.2-9.6)$ \\
$>2 \mathrm{y}(\mathrm{r})$ & & & \\
\hline
\end{tabular}

with shorter duration of marriage s (OR: 0.9, 95\% CI: $0.85-0.98)$ and 4.8 more times among females with their youngest child aged less than 2 years (OR: 4.8, 95\% CI: 1.9-11.9) (table 3).
Unmet need $=12+7+20=39(9.8 \%)$

Met need $=274(68.5 \%$ ) (Contraceptive prevalence rate)

Among all significant variables in univariate analysis, women working states and age of youngest child $<2$ years are found to be independent risk factors for unmet need for family planning, with estimated odds ratio of (2.46 and 3.39; respectively) as shown in logistic regression analysis (table 4).

\section{Discussion}

The concept of unmet need points to the gap between some women's reproductive intentions and their contraceptive behavior. Unmet need is an important indicator for measuring the progress of FP program and exploring the reasons of suboptimal FP practices which would further help to address the gap in service delivery. ${ }^{15}$ The current study reported that unmet needs among studied females represented $9.8 \%$, which is near to regional level in rural lower Egypt (10.3\%) reported by ElZanaty and way. ${ }^{6}$ In comparison, El-Masry et al reported that calculated the overall unmet need for FP was estimated as $11.2 \%$

Predicted $\%=87.5 \%$

in a study of rural married sexually active women in their childbearing period in another village in Dakahlia Governorate, Egypt. $^{7}$ The current result was higher than the overall rate of unmet need recorded by Sultan et al in Cairo, Egypt and Letamo \& Navaneetham in southern Africa in which the rates of unmet need were $(7.4 \%$ and $9.6 \%$; respectively). ${ }^{8,16}$ The difference in results could be explained by better appropriation of contraceptive methods in Cairo study and the lower total fertility rate in Botswana than Egypt (2.8 versus 3.5 births/women; respectively). However, the current rate of unmet need was lower than rates reported in previous studies conducted in other Egyptian Governorates by El-Gendy et al in Banha, Mohamed in Ismailia and Braghi et al in Assuit where the unmet need were $(30 \%, 15.7 \%$ and $24.5 \%$; respectively). $9, \quad 10,11$ The discrepancy in Assuit may be because of lower levels of contraceptive usage and higher fertility rates in Upper Egypt. In opposite to the current result the unmet need for family planning among rural married women was $26.1 \%$ in Ethiopia as reported by Solomon et al. ${ }^{17}$ The most 
frequent reasons for nonuse of contraception among females with unmet needs were fear of side effects $(43.5 \%)$, then infrequent sex (23\%), lactation $(20.5 \%)$, old age $(17.9 \%)$. These results run with that reported by El-Masry et al which found that more than half of women with unmet needs perceived that they were not at risk of pregnancy due to (infrequent sex $27.3 \%$, subfecundity $11.4 \%$, older age $6.8 \%$ ) while $25 \%$ recorded their fear of side effects and $15.9 \%$ reported resistance from husbands, religious prohibition was reported by only $6.8 \% .^{7}$ Also it was cited by Elweshahi et al that $35 \%$ of women with unmet need thought that lactation during the first year postpartum protect her from getting pregnant. ${ }^{18}$ Such common myths and lack of awareness among women in the post-partum period highlight the real need for community education about facts of birth control. The current study revealed that the risk of unmet need was higher among younger age woman and 2.5 more times among working women. These outcomes go with finding of Tadele et al in Ethiopia who detailed that age of women was statistically significant that an increase by one year of age of the women, the odds of being unmet need for family planning would be $20 \%$ less likely. ${ }^{19}$ Likewise, a demographic health survey comparative reports 34 in developing countries in 2014 revealed that unmet need to family planning was higher among younger women (age 15-19) than older women (age 20-24) as reported by Macquarrie and Dejenu et al. ${ }^{20,21}$ This might be younger age groups have no satisfactory data with respect to contraception and comprehensive education of sexuality. Regarding women working status, in accordance with our findings, El-Masry et $\mathrm{al}^{7}$ reported that working women were significantly higher among the unmet need group while it was disagreed with previous studies in Egypt by El- Gendy et al and Mohamed $^{9,10}$ and also by Vohra et al in India who concluded that there was no significant difference between both groups regarding their working status. ${ }^{22}$ In general, working women had greater chances to engage with the outside world, which exposed her to the others' ideas, experiences, and rumors about possible side effects of contraceptive methods hence avoid using them. Moreover, increased familial accountabilities both socially as well as economically could lead to unintended carelessness regarding using FP methods. ${ }^{7}$ The risk of unmet need was higher among women with shorter duration of marriage and 4.8 more times among females with their youngest child aged less than 2 years. This is due to fear from the side effects of contraceptive methods particularly hormonal methods during the period of breast feeding on breast milk secretion. These results run with that reported by El-Masry et al. ${ }^{7}$ However, Sultan et $\mathrm{al}^{8}$ found that age of the last child was not related with unmet need where there was greater understanding and better postpartum FP counseling services in urban than rural settings. In opposite to the current result, Braghi et al in Assuit found that unmet need was significantly associated with number of living children. ${ }^{11}$ Although, gender of living children had no statistically significant association with unmet needs among current studied females, previous Egyptian studies conducted by Sultan et al in Cairo and Mohamed in Ismailia showed that women with unmet needs considerably were having larger number of girls than met need group. ${ }^{8}, 10$ Also, Bhusal et al in Nepal showed that women with no sons had significantly higher among unmet need than those with met need group (69.6\% versus $30.4 \%){ }^{23}$ This may indicate that son preference behavior of couple may 
play significant role to determine unmet need for contraception.

After adjusting all significant variables in multiple logistic regression analysis, being working women and having the youngest child less than 2 years were found to be independent risk factors for unmet need for family planning and these results were similar to some extend to that reported by El-Masry et al. ${ }^{7}$ Women's age, their region of residence (rural/urban), education, number of living children, wealth status of their households, education of their husbands, fear of side effects, their employment status and exposure to mass media have been identified as important independent risk factors of unmet need for family planning among married women in Pakistan as reported by Asif and Pervaiz. ${ }^{24}$

\section{Conclusion}

The present study mainly concluded that the prevalence of unmet need for family planning among sexually active married women of reproductive age (18-49 years) in Shoha village was $9.8 \%$ with the most common reasons cited being fear of side effects $(43.5 \%)$, then infrequent sex and lactation (23\% and 20.5; respectively). The risk of unmet need was 2.46 more times among working women and 3.39 more times among women whose age of their youngest child less than two years.

\section{Study limitation}

A relatively small sample size from only one primary health care Centre. The study was conducted in rural area only and so the results couldn't be generalized as the women residing in rural areas are more likely to have unmet need for family planning as compared with women living in urban areas. The role of husband and type of family (nuclear or extended (joint) family) were not considered. Social desirability bias and recall bias might be introduced because, those pregnant and post-partum amenorrheic women were asked about their current and recent pregnancy; respectively. Therefore, they might not exactly remember or sometimes hide the wontedness or planned time of their pregnancy

\section{Recommendation}

Health education and counselling settings should be triggered to address the reasons behind increasing the prevalence of unmet need in rural area as fear of side effect of contraceptive methods is found to be an important factor behind non -use of the method. Younger married women deserve special consideration as unmet need is highest among them. More in depth studies with larger sample size and with interventional element to detect more reasons and risk factors of unmet need of family planning and find solutions to overcome this public health problem and its consequences. More effective FP program to address the problem in depth with targeting the husbands and involving them in FP programs.

Declaration of Conflicting Interests: The author(s) declared no conflicts of interest with respect to the authorship and/or publication of this article.

\section{References}

1. World Health Organization (WHO). Family planning fact sheet No 351. [Online] Available from:

http://www.who.int/mediacentre/factsheets/fs 351/en. World Health Organization. 2013.

2. Mutombo N, Bakibinga $P$, Mukiira C, Kamande E. Benefits of family planning: an assessment of women's knowledge in rural Western Kenya. BMJ Open. 2014;4(3):e004643.

3. Alkema L, Kantorova V, Menozzi C, Biddlecom A. National, regional, and global rates and trends in contraceptive prevalence and unmet need for family planning between 1990 and 2015: a systematic and 
comprehensive analysis. Lancet. 2013;381(9878):1642-52.

4. World Health Organization (WHO). Action Plan for Sexual and Reproductive Health: Towards achieving the 2030 Agenda for Sustainable Development in Europe leaving no one behind. WHO, 2016. 2016.

5. Westoff C. Unmet need for modern contraceptive methods: DHS Analytical Studies No. 28. Calverton: ICF International. 2012.

6. El-Zanaty F, Way A. Egypt demographic and health survey 2008. Egyptian: Ministry of Health. Cairo: El-Zanaty and Associates, and Macro International. 2009.

7. El-Bradley R, Essam N, Ghoneim M. Unmet need for family planning among women in rural Egypt. Int $\mathbf{J}$ Community Med Public Health 2018;5:1252-61.

8. Sultan MK, Bakr I, Ismail NA, Arafa N. Prevalence of unmet contraceptive need among Egyptian women: a community-based study. J prev med hyg. 2010;51(2):62-6.

9. El-Gendy SD, Dawah AY, Afify RHM, Taher SE, Omar R. Epidemiological study of the unmet need for contraception in Benha city. J Am Sci. 2012;8(5):125-34.

10. Adel N, Fiala L, Ekram A, Hassan F. The Unmet Need for Contraception among Married Women in Nefesha Village in Ismailia. Suez Canal University Medical Journal. 2013;19(2):127-42.

11.Braghi I, Gadallah M, Habil I. Prevalence and determinants of unmet need for contraception in a village population in Assiut Governorate-Egypt. The Egyptian J Community Med. 2013;31(1).

12.Sedgh G, Hussain R. Reasons for Contraceptive Nonuse among Women Having Unmet Need for Contraception in Developing Countries. Stud Family Plann. 2014;45(2):15169.

13.Daniel W. Biostatistics: A Foundation for analysis in the health sciences, 7th edR Wiley. New York. 1999:141-2.

14.Bradley SEK, Croft TN, Fishel JD, Westoff CF. Revising Unmet Need for Family Planning. DHS Analytical Studies No. 25. Calverton, MD: ICF International. 2012.
15.Mallick N, Paul B, Garg S, Dasgupta A, Ghosh A, Biswas B. Unmet need of family planning among married women of reproductive age: A clinic-based study in rural Bengal. Int J Med Sci Public Health. 2018:1.

16.Letamo G, Navaneetham K. Levels, trends and reasons for unmet need for family planning among married women in Botswana: a cross-sectional study. BMJ Open. 2015;5(3):e006603-e.

17. Solomon T, Nigatu M, Gebrehiwot TT, Getachew B. Unmet need for family planning and associated factors among currently married reproductive age women in Tiro Afeta District, South West Ethiopia, 2017: crosssectional study. BMC Women's Health. 2019;19(1).

18.Elweshahi HMT, Gewaifel GI, Sadek SSELD, El-Sharkawy OG. Unmet need for postpartum family planning in Alexandria, Egypt. Alexandria J Med. 2018;54(2):143-7.

19. Tadele A, Abebaw D, Ali R. Predictors of unmet need for family planning among all women of reproductive age in Ethiopia. Contracept Reprod Med. 2019;4(1).

20.MacQuarrie K. Unmet need for family planning among young women: Levels and trends. Rockville: ICF International (DHS Comparative Reports 34). 2014.

21.Dejenu G, Ayichiluhm M, Abajobir AA. Prevalence and associated factors of unmet need for family planning among married women in Enemay District, Northwest Ethiopia: a comparative cross-sectional study. 2013:4.

22. Vohra R, Vohra A, Sharma S, Rathore M, Sharma B, Sharma M. Determinants of the unmet need for family planning among women of Jaipur, Rajasthan. Int J Advanced Med Res 2014;1(1):20.

23.Bhusal CK, Bhattarai S. Factors Affecting Unmet Need of Family Planning Among Married Tharu Women of Dang District, Nepal. Int J Reprod Med. 2018;2018:1-9.

24.Asif MF, Pervaiz Z. Socio-demographic determinants of unmet need for family planning among married women in Pakistan. BMC Public Health. 2019;19(1). 